\title{
The pathogenesis of tropical spastic paraparesis/human T-cell leukemia type I-associated myelopathy
}

J. Casseb ${ }^{1,2}$ and

A.C. Penalva-de-Oliveira1,3

\section{Correspondence \\ J. Casseb \\ Laboratório de Alergia e Imunologia Clínica \\ Departamento de Dermatologia FM, USP \\ Av. Dr. Arnaldo, 455, Sala 2345 \\ 01246-903 São Paulo, SP \\ Brasil \\ Fax: +55-11-881-7190 \\ E-mail: j31@ hotmail.com}

Research partially supported by FAPESP (No. 99/11188-1) and CNPq (No. 150115/98-9).

Received December 10, 1999 Accepted August 14, 2000

\begin{abstract}
IInstituto de Moléstias Infecciosas "Emílio Ribas" and 2Laboratório de Alergia e Imunologia Clínica, Departamento de Dermatologia, Faculdade de Medicina, U niversidade de São Paulo, São Paulo, SP, Brasil 3UPC - U nidade de Pesquisa Clínica sobre STD/AIDS, Divisão de M oléstias Infecciosas, Departamento de Medicina Interna, Universidade Estadual de Campinas, Campinas, SP, Brasil
\end{abstract}

\section{Abstract}

Tropical spastic paraparesis/human T-cell leukemia type I-associated myelopathy (TSP/HAM) is caused by a human T-cell leukemia virus type I (HTLV-I) after a long incubation period. TSP/HAM is characterized by a chronic progressive paraparesis with sphincter disturbances, no/mild sensory loss, the absence of spinal cord compression and seropositivity for HTLV-I antibodies. The pathogenesis of this entity is not completely known and involves a multivariable phenomenon of immune system activation against the presence of HTLV-I antigens, leading to an inflammatory process and demyelination, mainly in the thoracic spinal cord. The current hypothesis about the pathogenesis of TSP/HAM is: 1) presence of HTLV-I antigens in the lumbar spinal cord, noted by an increased DNA HTLV-I load; 2) CTL either with their lytic functions or release/production of soluble factors, such as CC-chemokines, cytokines, and adhesion molecules; 3) the presence of Tax gene expression that activates $\mathrm{T}$-cell proliferation or induces an inflammatory process in the spinal cord; 4) the presence of B cells with neutralizing antibody production, or complement activation by an immune complex phenomenon, and 5) lower IL-2 and IFN- $\gamma$ production and increased IL-10, indicating drive to a cytokine type 2 pattern in the TSP/HAM subjects and the existence of a genetic background such as some HLA haplotypes. All of these factors should be implicated in TSP/HAM and further studies are necessary to investigate their role in the development of TSP/HAM.

\section{Key words}

- Tropical spastic paraparesis

- Human T-cell leukemia type I-associated myelopathy

- TSP/HAM

\section{Introduction}

Human T-cell leukemia virus type I (HTLV-I) is essentially a persistent slow virus with low virulence. However, a few individuals who have expressed disease related to this virus may show some immunopathological features such as $\mathrm{T}$ lymphocyte cell proliferation. This is mainly due to high interleukin (IL)-2 production found in some of these HTLV-I-infected subjects. In fact, IL-2 and its receptor (IL-2R) have the strongest capacity to cause activation, proliferation, and differentiation of $\mathrm{T}$ cells (1). Two pathways are possible: 1 ) the T cells are normal and 2) the $T$ cells present with genetic de- 
fects with a possible neoplastic outcome. The latter condition correlates with the appearance of adult T-cell leukemia (ATL), a highly pathogenic process often leading to death within a few months, regardless of therapy (2).

Tropical spastic paraparesis/HTLV-I-associated myelopathy (TSP/HAM) is a neurologic disease that, as reported in a survey conducted in Japan, developed in 14 of 1464 HTLV-I-infected individuals after a long incubation period, with an average age at onset of 43 years (3). The major neurological features of TSP/HAM consist of spasticity of the lower extremities, urinary bladder disturbances, lower extremity muscle weakness, and sensory disturbances with poorly defined thoracic sensory levels $(4,5)$. The major findings are mainly an inflammatory and demyelinating process located in the thoracic spinal cord $(6,7)$. A high concentration of $\mathrm{T}$ cells and monocytes is found in this area, but no evidence of malignancy has been described in these cells (8-10). Since the histopathologic process in TSP/HAM is essentially inflammatory, the pathway of HTLV-I in causing this disease differs from that of ATL.

\section{Mechanisms for TSP/HAM pathogenesis}

The possible mechanism by which HTLVI infection contributes to the pathogenesis of TSP/HAM is unknown. It has been proposed that HTLV-I disease may result from the expression of a unique sequence called $\mathrm{pX}$ within the proviral genome (11). pX encodes a transcriptional activator known as Tax, which has been shown to induce a variety of host cellular genes including IL-2 and its receptor in vitro. This altered regulation of cellular genes by the $\mathrm{pX}$ transactivating element may begin a process of T-cell activation and proliferation with subsequent events leading to inflammatory nervous system damage in TSP/HAM or malignant transforma- tion in ATL (11).

In addition, recent findings suggest that immune activation may contribute to the histopathological changes in TSP/HAM. Mononuclear inflammatory lesions have been observed in the central nervous system (CNS), accompanied by lymphocytic perivascular cuffing $(12,13)$. It has been demonstrated that the activated cellular immune state in TSP/HAM is virally driven by the concomitant expression of HTLV-I pX mRNA and the upregulation of IL-2 and IL$2 \mathrm{R} \alpha$ in these patients. Thus, TSP/HAM and seropositive carriers may represent an autocrine phase of HTLV-I infection, where $\mathrm{pX}$ gene activity induces the production of IL-2 and its receptor leading to polyclonal T-cell proliferation. In contrast, there was no evidence of $\mathrm{pX}$ or IL-2 transcription or spontaneous proliferation in ATL peripheral blood mononuclear cells (PBMC) despite very high levels of IL-2R $\alpha$ expression and soluble IL$2 \mathrm{R}$ in these patients (12).

In fact, it has been estimated that HTLVI integration is present in 3 to $15 \%$ of TSP/ HAM PBMC. An elevated CD4/CD8 ratio associated with the presence of activated $T$ cells with a high level of DR expression was observed in most patients. Recently, it has been shown that HTLV-I proviral DNA and a high frequency of viral-positive PBMC are higher in individuals with TSP/HAM or their relatives than in HTLV-I carriers. These data agree with the idea that HTLV-I viral load is important for the appearance of the neurological symptoms (14-16). This hypothesis may be tested with the use of highly active antiretroviral therapy against human immunodeficiency virus type 1 (HIV-1), which has led to improvement of some patients with TSP who were coinfected with HIV-1/ HTLV-I (Casseb J and Penalva-de-Oliveira AC, unpublished data).

An autoimmunity phenomenon may contribute to the pathogenesis of TSP/HAM. It has been observed that HTLV-I proviral DNA was detected only in the nucleus of lympho- 
cytes that infiltrated into the spinal cord. However, no proviral DNA was amplified in any neuronal cells, including neurons and glial cells. This indicates that demyelination of the spinal cord by HTLV-I is unlikely to be the result of viral infection of oligodendrocytes or neuronal cells. These findings suggest an autoimmune mechanism in TSP/ HAM (17) and that this neuronal process may be associated with an activated cellular and antibody-mediated immune response in these patients.

In one study, IgG isolated from TSP/ HAM patients was immunoreactive with uninfected neurons and this reactivity was HTLV-I specific. It has been shown that staining of CNS tissue with a monoclonal antibody to HTLV-I Tax, an immunodominant HTLV-I antigen, mimicked TSP/HAM IgG immunoreactivity. Absorption of TSP/ HAM IgG with recombinant HTLV-I Tax protein or preincubation of CNS tissue with the monoclonal antibody to HTLV-I Tax abolished the immunocytochemical and Western blot reactivity of TSP/HAM IgG. These data indicate that TSP/HAM patients develop an antibody response that targets uninfected neurons, yet reactivity is blocked by HTLV-I, suggesting viral-specific autoimmune reactivity to the CNS (18).

More recently, it has been shown that HIV-1, a lentivirus belonging to the same family as HTLV-I, possesses the capacity to induce high production of some chemokines, such as RANTES (regulated on activation, normal $\mathrm{T}$ cell expressed and secreted), macrophage inflammatory protein (MIP)- $1 \alpha$, MIP-1 13 and others, which are the natural ligands of the CC-chemokine receptors CCR5 (19). These are inflammatory proteins which seem to have antiviral capacity and are produced by monocytes, CD8 $+\mathrm{T}$ cells, and also by natural killer cells during TSP/ HAM process (20-22). Therefore, it has been hypothesized that an additional mechanism for TSP/HAM might be the presence of a similar stimulus, with cellular infiltration in the spinal cord in some HTLV-I carriers. Furthermore, adhesion molecules such as lymphocyte function-associated antigen-1 (LFA-1), Mac-1, very late antigen (VLA-4), intercellular adhesion molecule 1 (ICAM1 ), and vascular cell adhesion molecule 1 (VCAM-1) also have been strongly expressed in mononuclear cells infiltrating the spinal cords of TSP/HAM patients (23).

However, this does not explain why cellular infiltration is specifically located in the thoracic spinal cord, or why HIV-1-infected individuals have not shown a similar pattern of myelopathy. One possible explanation is that TSP/HAM usually occurs after a long incubation period and HIV-1-infected carriers may have a shorter life span than HTLVI-infected carriers. Another explanation may be that HIV-1 or its proteins do not have cell tropism for this region of the spinal cord.

In addition to the role of adhesion molecules, it has been published that matrix metalloproteinases (MMPs) and their inhibitors (TIMPs) known to be fundamental for normal physiological processes also contribute to several pathologies associated with uncontrolled tissue degradation. It has been reported that cytokines secreted by infected glial cells are responsible for the increased expression of MMP-3, MMP-9 and TIMP-3, while MMP-2, TIMP-1 and TIMP-2 remained stable in human and rat glial cells infected with HTLV-I. The role of dysregulated MMPs/TIMPs in the pathogenesis of TSP/ HAM may be related to various functions of these proteases, namely degradation of the blood-brain barrier, myelin constituent cleavage and conversion of the inactive TNFprecursor to the active form (24).

Specific cytotoxic T lymphocytes (CTL) play an important role in viral infections, especially retroviral infections, and HTLV-I Tax11-19-specific cytotoxic $T$ cells have been isolated from HLA (histocompatibility leukocyte antigen) A2-positive patients. It has been found that TSP/HAM patients carried a significant number (14\%) of CD8+ lympho- 
cytes specific for the HTLV-I Tax11-19 peptide in their peripheral blood. Simultaneous comparison of peripheral blood and cerebrospinal fluid (CSF) from one patient revealed 2.5-fold more Tax11-19-specific $\mathrm{T}$ cells in the CSF (24 vs 9\% in peripheral blood lymphocytes). Further analysis of HTLV-I Tax11-19-CTL in TSP/HAM patients showed different expression patterns of the activation markers intracellular TNF$\alpha$ and IFN- $\gamma$ depending on the severity of the disease. Thus, visualization of antigen-specific $\mathrm{T}$ cells demonstrates that HTLV-I Tax11-19-specific CD8+ T cells are activated, persist during the chronic phase of the disease, and accumulate in CSF (25).

In addition to having lytic characteristics, CTL or other mononuclear cells also are an important source of proinflammatory soluble mediators that may significantly contribute to the pathogenesis of TSP/HAM (26). In one study, infection with HTLV-I enhanced the secretion of IL-6 in human microglial cell-enriched cultures but did not stimulate the release of IL-1 from monocytes or microglial cells. Since both TNF- $\alpha$ and IL-6 have been implicated in inflammatory demyelination and gliosis, it has been suggested that human microglial cells and monocytes infected with and activated by HTLVI could play a role in the pathogenesis of TSP/HAM $(27,28)$.

Another soluble factor like transforming growth factor-beta (TGF- $\beta$ ) is responsible for regeneration of damaged tissues in the spinal cord and may attract more HTLV-I antigens to the CSF. In fact, it has been shown that the proliferative response of CD8+ cells against cultured and irradiated autologous CD4+ cells possessing HTLV-I antigens was significantly inhibited by TGF$ß 1$. However, the in vitro activation of HTLVI, which was evaluated by spontaneous proliferation of CD4+ cells, was unaffected by TGF- 31 . The induction of intracytoplasmic HTLV-I antigens in cultured CD4+ cells was facilitated by TGF- $\beta 1$ in a dose-dependent manner. Therefore, TGF- $\beta$ may have a critical role in localized viral activation within the CNS in patients with TSP/HAM (29).

The humoral system also plays an important role in TSP/HAM pathogenesis and complement via the classical pathway activation cascade may contribute to the inflammatory process seen in this disease (30). The presence of IgM and high titers of IgG and IgA antibodies to HTLV-I proteins, mainly to Tax protein, together with an increased HTLV-I proviral DNA load, seems to be related to the pathogenesis of TSP/HAM (31). However, higher antibody levels may be related to the higher viral load seen in TSP/HAM patients, without necessarily being harmful or causing the disease.

In addition to the induction of IL-2 and its receptor in TSP/HAM, there are genetic factors that may confer a heightened immune response against HTLV-I on these patients. For example, TSP/HAM-associated haplotypes were found in $70 \%$ of Japanese patients with TSP/HAM but not in individuals with ATL (30). Also, peripheral blood lymphocytes bearing these haplotypes exhibited a higher immune response to HTLVI antigen whereas the ATL-associated haplotypes had a lower response (32).

It was observed that $32 \%$ of the TSP/ HAM patients produced allolymphocytotoxic antibodies reactive with peripheral blood lymphocytes (mainly $\mathrm{T}$ cells) as well as B cells, which belonged to the IgM class, reacted under warm and cold conditions, and showed specificity for multiple HLA antigens, especially HLA A2, A26, A33, B7, B27, B35, B48, B61 and Cw3. Therefore, it may be suggested that either anti-HLA class I antibodies or antibodies cross-reactive with HLA were present. Weak cytotoxic antibodies were detectable in $14 \%$ of the sera from carriers. The production of allolymphocytotoxic antibodies in TSP/HAM patients may therefore be explained by the presence of allogeneic-like stimuli in this disease. HTLVI-infected cells expressing altered HLA anti- 
Table 1 - Characteristics of tropical spastic paraparesis/human T-cell leukemia type I-associated myelopathy (TSP/HAM) and adult T-cell leukemia (ATL).

\begin{tabular}{llll}
\hline Characteristic & TSP/HAM & ATL & Reference \\
\hline Underlying lesion & Inflammatory process, demyelination & Neoplastic & $2,6,7$ \\
Characteristic in host & High viremia PBMC/CNS & Low viral load & 12,14 \\
Genetic background & HLA A2, A26, A33, B7, B27, & DRB1*1101-DRB1*0301, & $31-33$ \\
& B35, B48, B61, CW3 & DRB1*1501-DQB1*0602 & \\
Frequency of disease & 14/1464 & 1/10,000 & 3,6 \\
Activation & IL-2, IL-2R, IL-6, TNF- $\alpha$, & IL-2, IL-2R soluble & $11,18-20,27$ \\
& CC-chemokines, TGF-ß & & \\
Apoptosis & Not altered & Decreased & 17 \\
Treatment & Anti-inflammatory, myorelaxant & Antiretroviral & 17 \\
Prognosis & Fair & Poor & 2,6
\end{tabular}

gens could possibly account for this stimulation $(33,34)$. However, in another study (35), individuals expressing the class I HLA allele HLA-A $* 02^{+}$may prevent $28 \%$ of potential cases of TSP/HAM, and HTLV-I-symptomatic carriers have a proviral load one-third that of HLA-A*02- HTLV-I carriers. These findings imply that a strong persistent classI-restricted CTL response to HTLV-I benefits the host by reducing the viral load.

Table 1 shows some characteristics of TSP/HAM and ATL and Figure 1 illustrates the possible mechanisms for the TSP/HAM process. The CTL-activated and HTLV-Iinfected $\mathrm{T}$ cells migrate to the CNS and infect resident cells and these cytotoxic CD8 $T$ cells may then recognize viral antigens on HTLV-I-infected CNS cells causing cellmediated cytotoxic demyelination. However, there may not be a CTL-specific action against CNS cells. Thus, the presence of IFN- $\gamma$-secreting HTLV-I-infected T cells and their recognition by virally specific CD8 $\mathrm{T}$ cells in the CNS induce microglia to secrete cytokines, such as TNF- $\alpha$ and IL-6, which may be toxic for myelin $(35,36)$. Also, autoimmune mechanisms may exist, with the occurrence of a) virally reactive $T$ cell crossreaction with a CNS antigen, or b) random infection of $T$ cells eventually resulting in the infection of CNS-autoreactive T cells. These, in turn, by virtue of the productive HTLV-I infection, become activated, expand

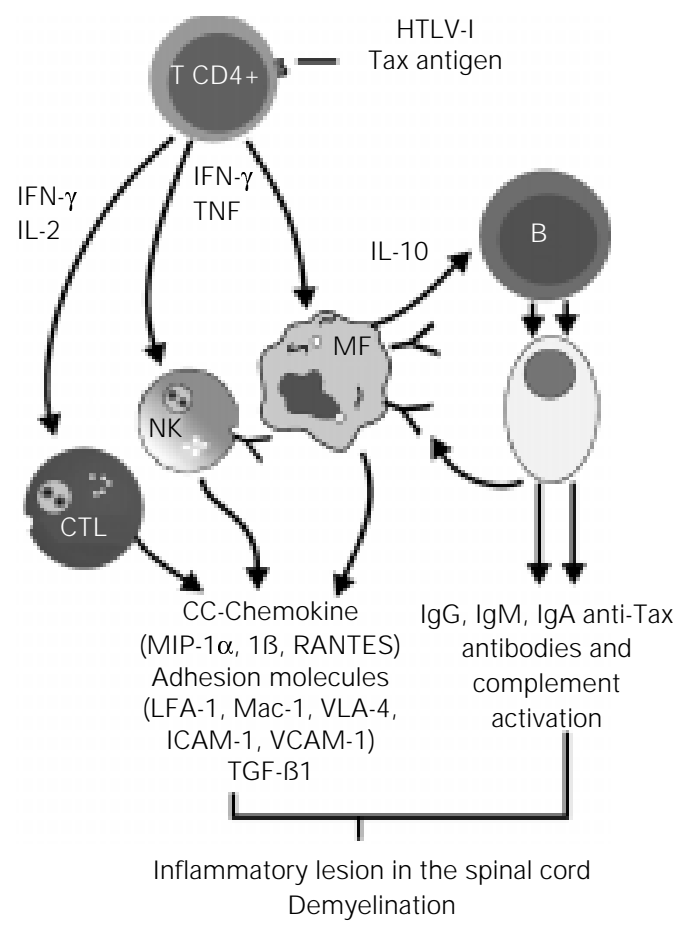

and migrate to the CNS, where they encounter their antigen, with the consequent occurrence of a specific immune response and demyelination. The existence of a genetic background, such as the presence of some HLA haplotypes (31-35), may have some implication for host susceptibility.

Finally, low CTL responders to HTLV-I develop a high proviral load which results in widespread chronic infection activation of $\mathrm{T}$ cells (36). Thus, an immune dysregulation with overproduction of IL-2 by T cells, which
Figure 1 - Model for the pathogenesis of tropical spastic paraparesis/HTLV-I-associated myelopathy. CTL, Cytotoxic T lymphocyte; NK, natural killer cell; MF, macrophage. 
can attract even more cells, stimulating production of other cytokines such as IFN- $\alpha$ or overexpression of some adhesion molecules may play an important role in TSP/HAM $(37,38)$. In contrast, our preliminary observations have shown that PBMC obtained from 2 TSP and HIV-1/HTLV-I-infected patients showed higher IL-10, lower IL-2 and IFN- $\gamma$ levels compared to asymptomatic HTLV-I carriers. These findings may indicate that a switch to a predominant cytokine type 2 pattern is observed in TSP/HAM with HIV-1 and HTLV-I infection $(39,40$, and Casseb J, Abadalla L, Montanheiro P and
Duarte AJS, unpublished data). Indeed, these data need further studies.

In conclusion, TSP/HAM pathogenesis is a multivariable phenomenon of immune system activation against the presence of HTLV-I antigens, leading to an inflammatory process and demyelination in the spinal cord of some HTLV-I-infected carriers.

\section{Acknowledgments}

We thank Dana Gallo for a critical revision of this manuscript.

\section{References}

1. Aboulafia DM (1995). Clinical implications of human T-cell leukemia virus type I/IIassociated diseases. AIDS Reader, 5: 118125.

2. Uchiyama T, Yodoi J , Sagawa K, Takatsuki K \& Uchino H (1977). Adult T-cell leukemia: clinical and hematologic features of 16 cases. Blood, 50: 481-492.

3. Osame M, J anssen R, Kubota $H$, Nishitani H, Igata A, Nagataki S, Mori M, Goto I, Shimabukuro H \& Khabbaz R (1990). Nationwide survey of HTLV-I-associated myelopathy in J apan: association with blood transfusion. Annals of Neurology, 28: 5056.

4. Gessain A, Barin F, Vernant J C, Gout O, Maurs L, Calender A \& de The G (1985). Antibodies to human T-lymphotropic virus type-I in patients with tropical spastic paraparesis. Lancet, 2: 407-410.

5. Osame M, Usuku J, Izumo S, ljichi N, Amitani $\mathrm{H}$, Igata $\mathrm{A}$, Matsumoto $\mathrm{M} \&$ Tara M (1985). HTLV-I-associated myelopathy: a new clinical entity. Lancet, 1: 10311032.

6. Gessain A \& Gout O (1992). Chronic myelopathy with human T-lymphotropic virus type I (HTLV-I). Annals of Internal Medicine, 117: 933-946.

7. Iwasaki Y (1990). Pathology of chronic myelopathy associated with HTLV-I infection (TSP/HAM). J ournal of Neurological Sciences, 96: 103-123.

8. Seiki M, Hattori S, Hirayama Y \& Yoshida M (1983). Human adult T-cell leukemia virus: complete nucleotide sequence of the provirus genome integrated in leukemia cell DNA. Proceedings of the National Academy of Sciences, USA, 80: 36183622.
9. Murphy EL \& Blattner WA (1988). HTLV-Iassociated leukemia: a model for chronic retroviral diseases. Annals of Neurology, 23: S174-S180.

10. Piccardo $P$, Ceroni $M$, Rodgers-J ohnson P, Mora C, Asher DM, Char G, Gibbs J r CJ \& Gajdusek DC (1988). Pathological and immunological observations on tropical spastic paraparesis in patients from J amaica. Annals of Neurology, 23: 156-160.

11. Azizuki $S$, Nakasato $O$, Higuchi $Y$, Tanabe K, Setoguchi M, Yoshida S, Miyazaki Y, Yamamoto S, Sudou S, Sannomiya K \& Okajima T (1987). Necropsy findings in HTLV-I associated myelopathy [Letter]. Lancet, 1: 156-157.

12. Tendler GL, Greenberg SJ, Blattner WA, Manns A, Murphy E, Fleisher T, Hanchard B, Morgan O, Burton J D, Nelson DL \& Waldmann TA (1990). Transactivation of interleukin 2 and its receptor induces immune activation in human T-cell lymphotropic virus type l-associated myelopathy: Pathogenic implications and a rationale for immunotherapy. Proceedings of the National Academy of Sciences, USA, 87: 5218-5222.

13. Cheng H, Tranok J \& Parks WP (1998). Human immunodeficiency virus type 1 genome activation induced by human Tcell leukemia virus type 1 tax protein is through cooperation of NF-kB and tat. J ournal of Virology, 72: 6911-6916.

14. Gessain A, Saal F, Gout $O$, Daniel MT, Flandrin G, de The G, Peries J \& Sigaux F (1990). High human T-cell lymphotropic virus type I proviral DNA load with polyclonal integration in peripheral blood mononuclear cells of French West Indian, Guianese, and African patients with tropi- cal spastic paraparesis. Blood, 75: 428433.

15. Nagai M, Usuku K, Matsumoto W, Kodama D, Takenouchi TM, Hashiguchi S, Ichinose $\mathrm{M}$, Bangham $\mathrm{C}$, Izumo $\mathrm{S} \&$ Osame M (1998). Analysis of HTLV-I proviral load in 202 TSP/HAM patients and 243 asymptomatic HTLV-I carriers: high proviral load strongly predisposes to TSP/HAM. J ournal of Neurovirology, 4: 586-593.

16. Manns A, Miley J W, Wilks J R, Morgan OC, Hanchard B, Warfe G, Cranston B, Maloney E, Welles LS, Blattner AW \& Waters D (1999). Quantitative proviral DNA and antibody levels in the natural history of HTLV-I infection. J ournal of Infectious Diseases, 180: 1487-1493.

17. Hara H (1994). Autoimmune mechanism in TSP/HAM. Nippon Rinsho, 52: 29192925.

18. Levin MC, Krichavsky M, Berk J, Foley S, Rosenfeld M, Dalmau J , Chang G, Posner J B \& J acobson S (1998). Neuronal molecular mimicry in immune-mediated neurologic disease. Annals of Neurology, 44: 87-98.

19. Hoffman TL \& Doms RW (1998). Chemokines and coreceptors in HIV/SIV-host interactions. AIDS, 12 (Suppl A): S17-S26.

20. Copeland KFT \& Heeney J L (1996). T helper cell activation and human retroviral pathogenesis. Microbiological Reviews, 60: 722-742.

21. Oliva A, Kinter AL, Vaccarezza M, Rubbert A, Catanzaro A, Moir S, Monaco J , Ehler L, Mizell S, J ackson R, Li Y, Romano J W $\&$ Fauci AS (1998). Natural killer cells from human immunodeficiency virus (HIV)-infected individuals are an important source of CC-chemokines and suppress HIV-1 en- 
try and replication in vitro. J ournal of Clinical Investigation, 102: 223-231.

22. Umehara F, Izumo S, Takeya M, Takahashi K, Sato E \& Osame M (1996). Expression of adhesion molecules and monocyte chemoattractant protein-1 (MCP-1) in the spinal cord lesions in HTLV-I-associated myelopathy. Acta Neuropathologica, 91: 343-350.

23. Giraudon $P$, Buart $S$, Bernard A \& Belin MF (1997). Cytokines secreted by glial cells infected with HTLV-I modulate the expression of matrix metalloproteinases (MMPs) and their natural inhibitor (TIMPS): possible involvement in neurodegenerative processes. Molecular Psychiatry, 2: 107-110.

24. Greten TF, Slansky J E, Kubota R, Soldan SS, J affee EM, Leist TP, Pardoll DM, J acobson S \& Schneck J P (1998). Direct visualization of antigen-specific $T$ cells: HTLV-1 Tax11-19-specific CD8(+) T cells are activated in peripheral blood and accumulate in cerebrospinal fluid from TSP/ HAM patients. Proceedings of the $\mathrm{Na}-$ tional Academy of Sciences, USA, 95: 7568-7573.

25. Biddison WE, Kubota R, Kawanishi T, Taub DD, Cruikshank WW, Center DM, Connor EW, Utz U \& J acobson S (1997). Human T cell leukemia virus type I (HTLVI)-specific CD8+CTL clones from patients with HTLV-I-associated neurologic disease secrete proinflammatory cytokines, chemokines, and matrix metalloproteinase. J ournal of Immunology, 159: 20182025.

26. Hoffman PM, Dhib-J albut S, Mikovits J A, Robbins DS, Wolf AL, Bergey GK, Lohrey NC, Weislow OS \& Ruscetti FW (1992). Human T-cell leukemia virus type I infection of monocytes and microglial cells in primary human cultures. Proceedings of the National Academy of Sciences, USA, 89: 11784-11788.

27. Fox RJ , Levin MC \& J acobson S (1996). Tumor necrosis factor alpha expression in the spinal cord of human T-cell lympho- trophic virus type I associated myelopathy/tropical spastic paraparesis patients. J ournal of Neurovirology, 2: 323-329.

28. Nagai $M$, ljichi $S$, Hall WW \& Osame M (1995). Differential effect of TGF-beta 1 on the in vitro activation of HTLV-I and the proliferative response of CD8+ T lymphocytes in patients with HTLV-I-associated myelopathy (TSP/HAM). Clinical Immunology and Immunopathology, 77: 324-331.

29. Saarloos MN, Koenig RE \& Spear GT (1995). Elevated levels of iC3b and C4d, but not $\mathrm{Bb}$, complement fragments from plasma of persons infected with human $T$ cell leukemia virus (HTLV) with HTLV-Iassociated myelopathy/tropical spastic paraparesis. J ournal of Infectious Diseases, 172: 1095-1097.

30. Lira J, Nakamura M, Sawada Y, Ohori N, Itoyama Y, Yamamoto N, Sakaki Y \& Goto I (1992). Antibody titers to HTLV-Ip40tax protein and gag-env hybrid protein in HTLV-I-associated myelopathy/tropical spastic paraparesis: correlation with increased HTLV-I proviral DNA load. J ournal of Neurological Sciences, 107: 98-104.

31. Usuku K, Sonoda S, Osame M, Yashiki S, Takahashi K, Matsumoto M, Sawada T, Tsuji K, Tara M \& Igata A (1988). HLA haplotype-linked high immune responsiveness against HTLV-I in HTLV-I-associated myelopathy: comparison with adult T-cell leukemia/lymphoma. Annals of Neurology, 23: 143-150.

32. Godoy AJ, Itoyama $Y$, Tokunaga K, Hara H, Kawaga Y, Kiyokawa H, Maeda Y \& Goto I (1994). Allolymphocytotoxic antibodies in sera from HTLV-I-associated myelopathy/tropical spastic paraparesis patients-putative anti-HLA antibodies. J ournal of Neurological Sciences, 125: 62-69.

33. Uchiyama T (1997). Human T cell leukemia virus type I (HTLV-I) and human diseases. Annual Review of Immunology, 15: 15-37.

34. Manns A, Hanchard B, Morgan OS, Wilks R, Cranston B, Nam J M, Blank M, Kuwayama M, Yashiki S, Fujiyoshi T,
Blattner W \& Sonoda S (1998). Human leukocyte antigen class II alleles associated with human T-cell lymphotropic virus type I infection and adult T-cell leukemia/ lymphoma in a Black population. J ournal of the National Cancer Institute, 90: 617622.

35. J effery KJM, Usuku K, Hall SE, Matsumoto W, Taylor GP, Procter J, Bunce M, Ogg GS, Welsh KI, Weber J N, Lloyd AL, Nowak MA, Nagai M, Kodama D, Izumo S, Osame M \& Bangham CRM (1999). HLA alleles determine human Tlymphotropic virus-I (HTLV-I) proviral load and the risk of HTLV-I-associated myelopathy. Proceedings of the National Academy of Sciences, USA, 96: 3848-3853.

36. Bangham CRM, Kermode AL, Hall SE \& Daenke S (1996). The cytotoxic T-lymphocyte response to HTLV-I: the main determinant of disease? Seminars in Virology, 7: 41-48.

37. Höllsberg P (1997). Pathogenesis of chronic progressive myelopathy associated with human T-cell lymphotropic virus type I. Acta Neurologica Scandinavica, 169 (Suppl): 86-93.

38. Elovaara I, Koenig S, Brewah AY, Woods RM, Lehky T \& J acobson S (1993). High human $T$ cell lymphotropic virus type 1 (HTLV-1)-specific precursor cytotoxic T lymphocyte frequencies in patients with HTLV-1-associated neurological disease. J ournal of Experimental Medicine, 177: 1567-1573.

39. Casseb J, Hong MA, Salomão S, Duarte AJ S, Gallo D \& Hendry RM (1997). Coinfection with human immunodeficiency virus and human T-cell lymphotropic virus type I: Reciprocal activation with clinical and immunological consequences. Clinical Infectious Diseases, 25: 12591260

40. Casseb J (1998). Is HTLV-I more clever than HIV-1? Clinical Infectious Diseases, 27: 1309-1310. 